\title{
Encountering Proportional Reasoning During a Single Algebra Lesson: A Microgenetic Analysis
}

\author{
Anna L. V. Lundberg ${ }^{1 *}$ (D) \\ ${ }^{1}$ Department of Pedagogical, Curricular and Professional Studies, Gothenburg University, Gothenburg, SWEDEN \\ *Corresponding Author: anna.lundberg@gu.se
}

Citation: Lundberg, A. L. V. (2022). Encountering Proportional Reasoning During a Single Algebra Lesson: A Microgenetic Analysis. International Electronic Journal of Mathematics Education, 17(1), em0673. https://doi.org/10.29333/iejme/11571

\begin{abstract}
ARTICLE INFO
Received: 7 Apr. 2021

Accepted: 6 Jan. 2022

ABSTRACT

This case study explores how 12-13-year-old students encounter proportional reasoning while working with geometric patterning tasks using concrete materials. The focus is on the students' use of spontaneous concepts when first dealing with such patterns in the context of collaborative work. Based on video recordings of a single lesson, a microgenetic analysis was performed to identify students' learning trajectories, starting with students familiarizing themselves with pattern structure, followed by engagement in proportional reasoning, and ending with students perceiving a new technique to handle a situation where proportional reasoning did not suffice. While some student groups were able to move along the whole trajectory, most groups, when facing challenges, regressed to simpler techniques. The results provide new insights into students' learning trajectories, which can be used to support students' progress in the context of student-teacher interaction.
\end{abstract}

Keywords: algebra, geometric pattern, learning trajectory, microgenesis, proportionality, proportional reasoning

\section{INTRODUCTION}

The concept of proportionality is fundamental not only within mathematics and science, but also in everyday life, for example in the context of unit prices, speed, mixtures and currency conversions. While the importance of proportionality in mathematics education is recognized, research indicates that many students have difficulties in learning and using proportional reasoning (e.g., Tjoe \& Torre, 2014). The difficulties can be related to how proportionality is presented in textbook tasks involving fractions, ratios, percentages and decimals in linear relationships (Lobato \& Ellis, 2010). Furthermore, textbooks provide limited support for students' development of mathematical structures (Vergnaud, 1983) necessary for the learning of proportional reasoning (Shield \& Dole, 2013). For example, there are limited opportunities for students to distinguish proportional from non-proportional situations in textbook tasks (Burgos \& Godino, 2020), and the intuitive approach to proportionality is also not recognized in the tasks presented in the textbooks. This article reports on an empirical study on how students (aged 12-13) in Sweden reason when they are confronted with two pattern tasks during one lesson, where the focus of the analysis is on indications of proportional reasoning as the learning processes occur. The description of these processes aims at providing information about the teaching and learning of proportional reasoning.

\section{Proportionality}

Proportionality has received considerable attention from researchers over the years. The major part of this research deals with how students learn about proportionality when they solve problems that require proportional reasoning (e.g., Tjoe \& Torre, 2014). However, the focus of current research is, according to Simon (2018), more on the outcome of the teaching than on analyzing the students' learning processes as they occur. Inspired by Simon's $(1995,2018)$ studies about learning trajectories, this study explores how far learning may develop in one class of students involved in collaborative work during a single 40-minute algebra lesson.

Proportionality tasks presented in school are usually designed as "missing value" or "numerical comparison" problems (Lundberg, 2011; Tjoe \& Torre, 2014). In this study, the students are working on "missing value" tasks of the type $a / b=c / d$, where one of the four natural numbers $a, b, c$, and $d$ is unknown. A substantial body of proportional reasoning research has shown that the ability to solve missing value problems may be considered as a relevant indicator of proficiency in proportional reasoning (Cramer \& Post, 1993). However, a focus in the teaching of proportional reasoning on the procedures of cross multiplication without an emphasis on an understanding of when and where proportional reasoning is relevant might be counterproductive. Indeed, data from several studies suggest that students sometimes use proportional reasoning in situations where it is not 
appropriate (e.g., Tjoe \& Torre, 2014). Thus, Lamon (2007) suggests that students' use of proportional reasoning in relevant contexts needs to be investigated.

\section{Research Context and Curricular Background}

The background to the present research is that, in the autumn of 2011, a new curriculum for the Swedish compulsory school came into force (Swedish National Agency for Education, 2011). The new curriculum was introduced simultaneously for all grades. One of the new directions in the curriculum is that proportionality is to be introduced as early as in Grades 1 to 3 as "proportional relationships" (Swedish National Agency for Education, 2011). Another new direction is that the concept of proportionality appears in the core content for Grades 4 to 6. In the previous curriculum (Swedish National Agency for Education, 2001), proportionality was introduced later, between Grades 6 and 9. This meant that in existing textbooks for the earlier grades, proportionality was not presented in specific chapters, and new textbooks were not introduced until the following spring. Therefore, the students in this study, which was carried out in the autumn of 2011, had not received any formal teaching about proportional reasoning. Given these developments, it is of interest to study how these students in Grade 6 handle proportionality and proportional reasoning in the context of algebra, where proportional relationships commonly appear. Although proportionality is not explicitly mentioned in the curriculum within the core content of "Algebra", there are textbook tasks that involve proportionality and that may be solved using proportional reasoning in algebra, for example in the context of patterns.

\section{LITERATURE REVIEW}

\section{Research on Students' Learning of Proportionality and Proportional Reasoning}

It has been observed that students have difficulties learning proportional reasoning between quantities (i.e., external ratios, such as kilometer per hour, kilogram per liter) (Lamon, 2007). In this study, the term proportional reasoning is used in line with the definition given by Lamon (2007, p. 638), according to which proportional reasoning means giving arguments for claims about relationships between two pairs of real numbers. It also concerns the ability to use these relationships in various settings. Of special interest in Lamon's (2007) definition of proportional reasoning, which emphasizes the ability to distinguish between linear functions $y=a x$ and affine functions $y=a x+b$, with $b \neq 0$, is that "part of understanding a concept is knowing what it is not and when it does not apply" (p. 647, italics in original). In the linear case, $y$ is proportional to $x$. In the affine case when $b \neq 0, y$ is not proportional to $x$ but the change $\Delta y$ of $y$ is proportional to the change $\Delta x$ of $x(\Delta y=a(x+\Delta x)+b-(a x+b)=a \cdot \Delta x)$. Research about solving arithmetic word problems has shown that students use improper applications of linearity, referred to as the illusion of linearity (Van Dooren et al., 2005). Burgos and Godino (2020) studied written solutions of missing value tasks, followed by interviews with Spanish students (aged 11-12). The authors found that students struggled to identify proportional situations as well as to discern the different quantities in the proportional relationship. Burgos and Godino (2020) recommend that teaching should include interaction and communication to detect students' intuitive strategies, i.e., how they find the unit value. Although extensive research has been carried out on how students use linear relationships in different situations, students' use of proportional reasoning during in situ lessons has not been given much attention in research. In an overview of overreliance on linearity, carried out by Van Dooren et al. (2008), the authors recommend further research on students' intuitive understanding of non-linearity.

\section{Geometric Patterning Tasks}

According to Mulligan and Mitchelmore (2009, p. 34), a mathematical pattern can be described as "any predictable regularity, usually involving numerical, spatial or logical relationships." In addition, a geometric ${ }^{1}$ pattern ${ }^{2}$ is defined by Strømskag Måsøval (2011) as a sequence of geometric configurations which grow according to a fixed rule. In the literature, there are few studies on how students develop their understanding of proportional reasoning when working with growing geometric patterning tasks, which is the focus of this study. The few reported studies in classroom environments (e.g., Wilkie, 2016) on this issue are often design studies, where researchers design teaching sequences with proportional reasoning in different ways, to test specific hypotheses about how instruction should be organized. The specific context of group work was not in focus for Wilkie's study.

Several studies concern students' reasoning using matchsticks in patterning tasks (e.g., Stacey, 1989). Stacey studied 9-13year-old students' responses to generalization tasks. One of these tasks asked for a description of the relation between the number of rungs $n$ and the number of matchsticks $f(n)$ in ladders. The relation can be described by an affine function $f(n)=3 n+2$, where $n=1,2, \ldots$ (see Figure 1 ).

Here $f(n)$ is clearly not proportional to $n$, but the increase $\Delta f(n)=3 \cdot \Delta n$ is proportional to $\Delta n$. The students' responses indicated that if counting was not feasible, they used relationships that only apply in situations of proportionality. It was appealing to the students to use proportionality, and some of them even changed their correct affine function when the questions became more advanced.

\footnotetext{
${ }^{1}$ Construction and description of simple geometric patterns are introduced in Grades 1-3 (Swedish National Agency for Education, 2011).

${ }^{2}$ Here I use "geometric pattern" whereas Strømskag Måsøval (2011) calls it "shape pattern".
} 


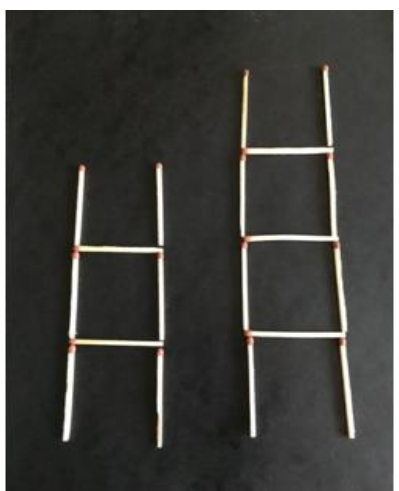

Figure 1. Two ladders built with matchsticks. Ladder pattern inspired by the work of Stacey (1989, p. 148)

Alternatively, the functional relationship in this example could be described by a recursive approach, focusing on the relationship between two subsequent figures in the sequence. For example, going from a ladder with two rungs and eight matchsticks in Figure 1 to a ladder with three rungs and 11 matchsticks, three matchsticks must be added: $f(3)=f(2)+3$.

Lannin et al. (2006) concluded in their study of 25 students' development and use of functional and recursive reasoning, that both are beneficial for higher education in mathematics. However, Küchemann (2010) suggests that students do not benefit from the recursive approach and recommends that teachers use tasks with a focus on identifying the structure of the geometric patterns. In addition, Wilkie (2016) studied 102 students, aged 12-13, in their first year in secondary school before the formal teaching of algebra. In one of the questions in a written questionnaire, the students were asked to notice the features of and to generalize a geometric matchstick pattern involving houses with connected walls in a row. A reported finding was that nearly 16 percent could find the number of sticks for seven houses but not for 17 houses. Wilkie suggests that either the pattern structure was not grasped or that there were difficulties in the calculations of the number of sticks. Wilkie also reported that even though the patterning task that was given after the house task had an everyday context with a restaurant table pattern, and students noticed the differences, 20 percent still struggled and used improper proportional reasoning.

Strømskag Måsøval (2011) suggests two different reasons for using geometric patterns to promote algebraic thinking: a) to provide a context for generalization and $b$ ) to provide the experience of mathematical structure. The latter is defined by Mason et al. (2009, p. 10) as "the identification of general properties which are instantiated in particular situations as relationships between elements." A (mathematical) pattern, then, is an enactment of a specific structure. When students solve patterning tasks and predict the structure of the general term, there must be some prior awareness of the structure that creates the given sequence, if the task is to be categorized as a mathematical patterning task. After the structure has been set, the first crucial step is to notice what varies and what is invariant in the set of objects (Kieran, 2018). Some researchers (e.g., Küchemann, 2010) conclude that structural awareness (or structure sense, see Lüken, 2012) may develop through manipulation and reconstruction of objects. In this context, Küchemann (2010) recommends teaching of geometric pattern tasks with a focus on the figural structure itself. This allows for scaffolding by the teacher to enable the students to focus on the pattern structure, when they are trying to establish the relation between the diagram number $n$ and $f(n)$, instead of focusing on the relation between the first and the next given diagram. A non-consecutive or single (with a generic description) display of a pattern thus seems to help students to look into the structure of the pattern. In the present study, patterning tasks are modelled by linear and affine functions with consecutive and nonconsecutive elements in the format of pattern display.

\section{METHODOLOGY}

\section{Studying Mathematical Development Within a Microgenetic Framework: Theoretical Assumptions and Research Questions}

According to the sociocultural and pragmatic perspectives, the development of cognitive processes takes place through social interaction and communication (Dewey, 1916/1980; Vygotsky, 1930/1978). Vygotsky (1930/1978) criticizes psychologists for not observing the initial steps of learning when a child tries to master a task. He suggests that development should be studied at the very moment when it occurs. Therefore, he expanded the microgenetic approach, a qualitative research method first used by Werner (1948), and points out that:

...we will want to study the reaction as it appears initially, as it takes shape, and after it is firmly formed, constantly keeping in mind the dynamic flow of the entire process of its development (Vygotsky, 1930/1978, p. 69).

Microgenesis, or microdevelopment, as it is referred to by Granott and Parziale (2002, p. 1), is defined as "the process of change in abilities, knowledge, and understanding during short time spans." By using a microgenetic approach in this study, it was possible to examine not only what knowledge students acquire, but also the early phases of progress in their reasoning, in line with the suggestions made by Vygotsky. In this study, I follow Säljö (1991) by using the term "learning" in the sense of an increasing capacity to find common patterns in unique problems. The students develop abilities by learning to master new cultural tools (in the present case mathematical concepts) that structure a given situation in a productive way. I use the term "cultural tool" in line 
with Wertsch (1985), who argues, along with Cole (1996), that the physical and conceptual/semiotic features of artifacts are closely linked.

Some mathematical concepts can appear both as a "spontaneous" and as a "scientific" concept (Vygotsky, 1934/1986, p. xxxiii). Teaching based on a spontaneous concept will pave the way for the shaping of the scientific concept connected to the former. When both the scientific and the spontaneous concepts are present, a "zone of proximal development" (ZPD) emerges, where the teacher can introduce the scientific concept to a student who is already familiar with the corresponding spontaneous concept. In the present study, ZPD is used to analyze students' learning of proportional reasoning during a lesson. I also study how the teacher scaffolds students during class (Säljö, 2011; Wood et al., 1976).

Del Río and Álvarez (2007) use the term "trajectories” to interpret Vygotsky's (1934/1986) statement that knowledge does not develop in a straightforward manner. The sociocultural perspective thus contributes conceptual tools to describe learning in terms of progression, as well as to analyze whether, and to what extent, the design of tasks allows the teacher to scaffold students when developing their capacities to engage in proportional reasoning.

More research is needed on learning trajectories in situ (Maloney et al., 2014). A similar term, learning progression, is mentioned within the tradition of science education (Lobato \& Walters, 2017). This study follows the recommendations by Weber et al. (2015) in separating learning trajectory from learning progression, as it focuses on how students' learning processes are developed, not to what extent students fulfill predefined goals. The present analysis has been based on the definition suggested by Confrey et al. (2009, p. 2):

A researcher-conjectured, empirically-supported description of the ordered network of experiences a student encounters through instruction (i.e. activities, tasks, tools, forms of interaction and methods of evaluation), in order to move from informal ideas, through successive refinements of representation, articulation, and reflection, towards increasingly complex concepts over time.

This definition recognizes tools as mediational artifacts as well as recognizing that learning is developed by students' pertinent experiences (Maloney et al., 2014). In this study, the definition has been broadened to focus on students at a group level by analyzing the development of their ways of handling proportional reasoning. Learning trajectory is thus a concept intended to describe students' learning processes. The present study uses the term learning trajectory as an analytical tool to document and review what happens when a group of students works with proportional reasoning. The learning trajectories are described in terms of modes of proportional reasoning, where students: a) use some elements of proportional reasoning, b) adjust their reasoning when faced with challenges in the tasks, and c) sometimes succeed in achieving increasingly powerful modes of reasoning.

The present article presents an empirical investigation of how a group of students in Grade 6 in Sweden, who have not previously been taught about proportionality, handle proportional reasoning when dealing with a geometric patterning task using concrete material (matchsticks). To observe the development of proportional reasoning "in the process of change" (Vygotsky, 1930/1978, p. 65), a microgenetic approach is used (see also Cole, 1996; Siegler, 2006), focusing on activities at the group level. The progress students make in their learning of proportional reasoning is described in terms of a learning trajectory. The two interconnected questions addressed in this study are:

1. RQ1. In what ways do students make use of proportional reasoning when working with geometric patterning tasks using material objects?

2. RQ2. What signs of learning of proportional reasoning are possible to discern during a lesson?

\section{Methods}

The research questions necessitate the use of case study as a method (Lincoln \& Guba, 1985). In addition to the use of learning trajectory as an analytical stance, concepts from the framework of Anthropological Theory of the Didactic (ATD) have been employed (Chevallard, 2006) as analytical tools.

\section{ATD: Two Theoretical Models of Proportionality}

To organize the mathematical content of this study and be able to describe the different methods that students use to solve the matchstick tasks, three concepts from ATD are used: theory, type of task, and technique (e.g., Chevallard et al., 2015, p. 2619). These are parts of a praxeology that links theoretical and practical dimensions of human activities (e.g., Chevallard, 2006). From this perspective, theory refers to certain conditions of an entity, the task is influenced by mathematics culture in general, and technique refers to ways of doing a task. The praxeology is embedded in a Reference Epistemological Model (REM) that is used to describe and analyze the mathematical content included in the teaching and learning processes (Bosch \& Gascón, 2006). In this study, a REM is of special relevance. It consists of two distinct theoretical models of proportionality as defined by Miyakawa and Winsløw (2009), within the ATD framework. The real variables $x$ and $y$ are called dynamically proportional if

$$
y=a \cdot x
$$

where the real number $a$ is called the constant of proportionality. The pairs $(a, b)$ and $(c, d)$ of positive real numbers are called statically proportional, denoted by $(a, b):(c, d)$, if $a \cdot d=b \cdot c$ or, equivalently,

$$
a / b=c / d
$$


There is a close connection between linear mappings of measure spaces (Kirsch, 1969; Vergnaud, 1983) and dynamic proportionality (with positive rational constants of proportionality) of positive rational variables in the above sense. The elements of a measure space $\mathfrak{B}$, have the form $q S$, where $S$ is the unit of measure and $q$ is a positive rational number. Assume that $\mathfrak{B}_{1}$ and $\mathfrak{B}_{2}$ are such measure spaces with units of measures $S_{1}$ and $S_{2}$ respectively. It is then straightforward to show that a mapping $\varphi$ from $\mathfrak{B}_{1}$ to $\mathfrak{B}_{2}$ such that $\varphi\left(S_{1}\right)=a S_{2}$, where $a$ is a positive rational number, is linear if and only if the coefficients $q$ and $p(q)$ of the elements $q\left(S_{1}\right)$ in $\mathfrak{B}_{1}$ and their image elements $p(q) S_{2}$ in $\mathfrak{B}_{2}$ under the mapping $\varphi$ are dynamically proportional, where $a$ is the positive rational constant of proportionality. This is analogous to the close connection between static proportionality in the above sense and static proportionality in measure spaces (for details, see Kirsch, 1969). The distinction between the number of matchsticks and the diagram number (i.e., which term in the pattern is in question), hence between elements of different measure spaces, supports the analysis of the matchstick task.

The above dual forms of the concept of proportionality reflect its use in mathematical teaching. Both forms cause problems for students (Lundberg, 2011). Proportionality has a background in Euclid's Elements, where it appears as static as in Formula 2 above (Euclid \& Heath, 1956; see also García, 2005, and Bosch, 1994). According to Lundberg (2011), many dictionaries use Formula 1 to define dynamic proportionality. One explanation for leaving out the static form in dictionaries could be difficulties connected to the static model, found and explored in research (e.g., Freudenthal, 1983; Lybeck, 1981). To clarify the difficulty, Freudenthal (1983) argued for categorizing ratios as internal or external. In the present study, a ratio is either used as a "multiplicative comparison of two quantities", or as a "joining of two quantities in a composed unit" (Lobato \& Ellis, 2010, p. 18). An internal proportionality is a relation between elements in the same measure space; an external proportionality is a relation between elements in different measure spaces. For example, if $\mathfrak{B}_{1}$ (meter) and $\mathfrak{B}_{2}$ (second) are the measure spaces, then ( $s_{1} /$ $\left.s_{2}=t_{1} / t_{2}\right)$ is an internal and $\left(s_{1} / t_{1}=s_{2} / t_{2}\right)$ an external proportionality, where $s_{1}$ and $s_{2}$ are elements of $\mathfrak{B}_{1}$ (meter), and $t_{1}$ and $t_{2}$ are elements of $\mathfrak{B}_{2}$ (second).

To explore the mental leap between reasoning about external proportionalities and internal proportionalities, Lybeck (1981) conducted an empirical study where upper secondary students were interviewed while they were solving tasks involving proportional reasoning. Lybeck found that a majority of students used internal proportionalities when solving the tasks. He concluded that the students intuitively used internal proportionalities and that without explicit teaching, they have difficulties using external proportionalities. This result was also confirmed in a study by Tjoe and Torre (2014) who concluded that students found internal ratios easier to solve in missing value tasks.

\section{Collection of Data}

The data for this study come from a large set of video recordings of algebra lessons gathered from multiple sources, at various times, within an international study ${ }^{3}$. The data corpus from which this lesson is chosen comprises 22 lessons video-recorded in Sweden. In addition to the videos, students' worksheets were collected. The video data were recorded using three video cameras following a) the teacher, b) one particular group with two students, selected by the teacher, and c) the whole class (fixed-focus camera) (cf. Heath et al., 2010). The recordings were made when the students' first lessons in algebra were conducted, as defined by the teacher.

The teacher of the chosen lesson was recruited through personal contacts and also because she had expressed interest in participating in a video research study. This teacher has a teaching diploma and 22 years of teaching experience. The 17 students aged 12 to 13, in the class observed are from the south of Sweden. The school's catchment area is predominantly middle class. The students in this study were organized by the teacher into seven groups with two members and one group with three members. The research team, in collaboration with the teacher, made a recording plan for four consecutive lessons. However, the teacher was free to plan and organize the lessons without interventions from the research team. In accordance with the requirements of the Swedish Research Council (2007), ethical clearance was sought from the students and their parents. All participants have been anonymized.

\section{Selection of Lesson}

Proportionality had recently been implemented in the Swedish curriculum but did not yet appear as an explicit concept in textbooks for this age group. I selected videos from the Swedish context for the study to have the opportunity to look at how students, who have not been formally taught about proportional reasoning, handle tasks where the use of proportional reasoning is a possibility. The criteria for the selection of a case when viewing these videos was to find episodes that were rich in the sense that students were trying to use proportional relationships when grappling with patterning tasks. For the analysis, the observed lesson data were organized into lesson graphs by the project members. The lesson content was listed and described in several ways: task examples, screenshots of the blackboard, and a timeline for the teacher's actions. To find lessons rich in proportional reasoning, theoretical models of proportionality were used (static and dynamic, see Formula 1 and Formula 2) when analyzing the tasks displayed in the lesson graphs. To identify episodes with proportional reasoning in the data in an unbiased way, a method similar to interaction analysis (Jordan \& Henderson, 1995), entailing collaborative viewing sessions, was used. In this study, the author and the other project members viewed the author's choice of video clips with tasks where proportional reasoning was involved. During these viewing sessions, the participants stopped the tape when they found something relevant to discuss. However, in the choice of video clips, some impact from the author's background as a teacher in mathematics cannot be neglected in the analysis (Goodwin, 1994). Based on the selection criteria mentioned above, one lesson, where the students worked with matchstick tasks involving challenging uses of proportional reasoning, was chosen as a case study.

\footnotetext{
${ }^{3}$ For further information about the project, see Kilhamn and Röj-Lindberg (2012).
} 


\section{Analysis of Data}

\section{Selection of unit of analysis}

According to Granott (1998, p. 42), "A unit of analysis is defined as the smallest part that retains the attributes of the whole." The units of analysis in this study are: the verbal interaction between teacher and students, and between students and students, besides the non-verbal interactions in terms of gestures and pointing, and, in addition, the use of artifacts (Säljö, 2009). The reason for this choice is that all students in the classroom collaborate in the social and physical context of the activity given by the teacher (i.e., they see, talk to and hear each other, and they constantly make use of material objects).

\section{Microgenetic analysis}

The combination of a microgenetic approach (Cole, 1996), and the techniques of a single case study approach (Lincoln \& Guba, 1985) provide the opportunity to observe, during a single lesson, how students encounter proportional reasoning. Also, it gives the opportunity to observe how students handle patterning tasks and alter their techniques (in the sense in which this term is used in ATD) when proportional reasoning does not prove to be successful.

The lesson was transcribed verbatim using data from all three cameras. The lesson lasted 45 minutes, and every utterance and written illustration about proportional reasoning provided by the teacher, or the students, was included in the transcript. To be able to catch the utterances from the teacher and as many students as possible, the software Transana ${ }^{\circledR 4}$ was used. This software makes it possible to show all three videos at the same time and thus allows the possibility of collecting and organizing video clips. The use of video recordings provides the opportunity to play sequences over and over again, and thus facilitates a detailed analysis (see e.g., Heath et al., 2011). The given tasks were analyzed using the REM with the two theoretical models of proportionality to establish how the teacher and the students worked with this concept. To document the development during a process of change, data from all students in the observed lesson were included. In line with Siegler (2006), the paths of change were carefully examined qualitatively, and the source and breadth of change in the analysis were noted through detailed transcriptions.

Spoken discourse usually begins with an initiating move (verbal or nonverbal), followed by a response and, most likely, a follow-up move in the conversation between participants (in this study, students and teacher). Therefore, the unit of analysis used is a sequence of at least three consecutive turns in utterances. This is in line with the recommendations of Wells (1999). Occasions with utterances in the observed data where the teacher and the students in interaction used techniques (in the ATD sense) for proportional reasoning were analyzed as occasions of static vs. dynamic proportional reasoning. The students' different techniques were compiled in a network. When a student group's technique coincided with those of other student groups, a cluster with the techniques was created in the network. These different clusters, with the same techniques, were then organized into modes modelling the learning trajectories (Confrey et al., 2009) of the student groups. In this study, three modes of proportional reasoning were identified and described as $\operatorname{Mode}_{n}, \mathrm{n}=1,2,3$.

\section{Description of the Lesson and Tasks}

The selected lesson begins with a short introduction of the Pattern 1 task (Figure 2) before the students start working individually with matchsticks to build the first three elements ( 5 minutes). This is followed by a short gathering of the whole class to discuss how many matchsticks the students used for the first three elements (1 minute). The teacher then asks the students to start their individual work with the $5^{\text {th }}, 10^{\text {th }}, 20^{\text {th }}$, and $50^{\text {th }}$ element in a table ( 5 minutes). After a class discussion ( 10 minutes), the teacher hands out the Fishermen's cottages task (Figure 3). The students work together in groups and are asked to draw tables for their results (12 minutes). The lesson ends with a class discussion and gathering of material (7 minutes), which is interrupted by the lunch break. The two patterning tasks, Diamonds and Fishermen's cottages, given for the lesson are shown in Figure 2 and Figure 3, respectively.

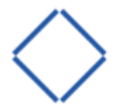

$\mathrm{D}_{1}$

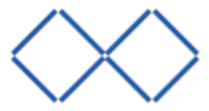

$\mathrm{D}_{2}$

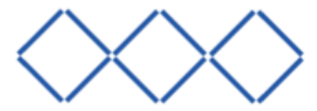

$\mathrm{D}_{3}$

Figure 2. Patterning task Diamonds used as Pattern 1 during the lesson

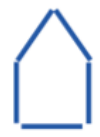

$\mathrm{D}_{1}$

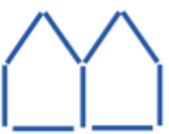

$\mathrm{D}_{2}$

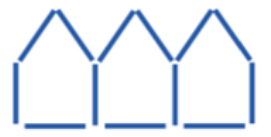

$\mathrm{D}_{3}$

Figure 3. Patterning task Fishermen's cottages used as Pattern 2 during the lesson

Both tasks given to the students involve building patterns described on an instruction sheet where matchstick diagrams $D_{1}$, $D_{2}$, and $D_{3}$ are illustrated. The label $D_{n}(n=1,2,3, \ldots)$ is used as a description of the individual terms or diagrams within a pattern (see Figure 2 and Figure 3). The written instructions on the blackboard are as follows (translated by author):

${ }^{4}$ Transana, version 2.42. (2010). This software has been developed by the Wisconsin Center for Education Research (WCER), University of Madison (USA), www.transana.org. 
Think about

\section{How many matchsticks do you need in Diagram 1?}

2. How many matchsticks do you always need for the next diagram?

A second tool, a table with given diagram numbers in the first row (here called $n, n=1,2,3,5,10,20$, and 50 ) with a space to fill in the sum of matchsticks (i.e., $f(n)$ ) in the second row, is introduced and drawn on the blackboard. Of interest here is the jump between $n=3$ and $n=5$, in line with the suggestion by Küchemann (2010) to use non-consecutive numbers, and the bigger jumps that follow to prompt generalization. The students explain how many matchsticks they need to build the diagram for each of the integers in the first row. In the introduction of the task, Pattern 2 (see Figure 3), students are asked to draw the corresponding table $(n, f(n))$ on a sheet of paper.

It should be noted that proportionality was not mentioned explicitly during the activity. This had the advantage of challenging the students to apply proportional reasoning notwithstanding the lack of previous instruction on proportions.

\section{Analysis of the patterning task Diamonds using the REM}

The task Pattern 1 can be interpreted as a type of "missing value" task because the question asked is: "How many matchsticks do you always need for the next diagram?" In mathematical terms, the situation is: $(1 / f(1)=3 / f(3))$, that is $(1 / 4=3 / x)$, where $x$ is the missing value. The task could also be interpreted recursively as $f(n+1)=f(n)+4$, with $f(1)=4$; thus $f(2)=$ $4+4=2 \cdot 4, f(3)=2 \cdot 4+4=3 \cdot 4$, and so on leading to $f(n)=n \cdot 4$, or $f(n) / n=4$, in the above formulation $n / f(n)=1 / 4$.

The analysis of the task implicitly highlights the two types of proportionality mentioned above, that is, dynamic and static proportionality (Miyakawa \& Winsløw, 2009). Because the individual diamonds in the pattern have no shared matchsticks between them, the function $f$ is linear. The proportionality factor in the dynamic proportionality model can be determined by the knowledge of the external relationship $f(n) / n$ for just one pair of values of $f(n)$ and $n$ (see Formula 1). In contrast, static proportionality can be applied using both an external relationship $f\left(n_{1}\right) / n_{1}=f\left(n_{2}\right) / n_{2}$ and an internal relationship $n_{1} / n_{1}=$ $f\left(n_{1}\right) / f\left(n_{2}\right)$ for any integers $n_{1}$ and $n_{2}$ (see Formula 2). Consequently, both theoretical models, static and dynamic proportionality, are possible in the Pattern 1 task. For $n=1,2, \ldots$ I consider the diagram number $n$ as the element $n[1]$ of a measure space $\mathfrak{B}_{1}([1])$ with the unit [1] and the number $f(n)$ of sticks in $D_{n}$ as the element $f(n)$ [stick] of a measure space $\mathfrak{B}_{2}$ ([stick] )with the unit [stick]. Static proportionality can be used both as an external and an internal relationship with respect to the measure spaces $\mathfrak{B}_{1}$ and $\mathfrak{B}_{2}$, whereas dynamic proportionality by definition is an external relationship between these measure spaces (see Table 1 ).

Table 1. Examples of calculation for analysis of the possibilities for the use of REM (i.e., dynamic and static proportionality) when working with the task Pattern 1

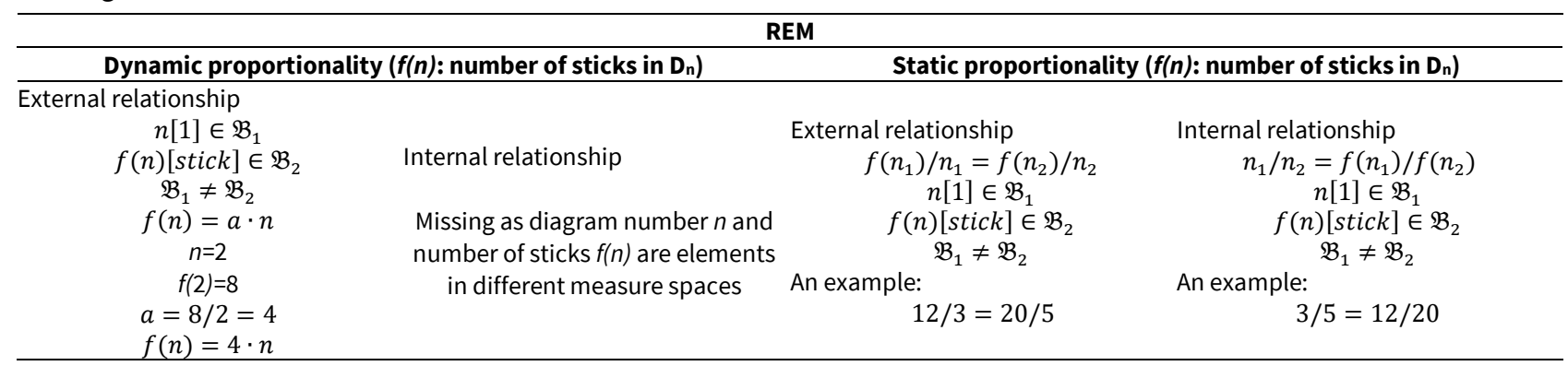

\section{Analysis of the patterning task Fishermen's cottages using the REM}

The task Pattern 2 differs from the task Pattern 1 in two respects:

1. D contains 5 matchsticks.

2. Two adjacent cottages in any diagrams $D_{n}, n \geq 2$, have one shared matchstick.

The task Pattern 1 offers opportunities for students to handle proportional reasoning with the two theoretical models static and dynamic proportionality, whereas proportional reasoning is not directly applicable in the task Pattern 2 . The tasks differ in that the function $f$ in the task Pattern 1 is linear $(f(n)=4 \cdot n, n=1,2, \ldots)$ while in the task Pattern 2 , it is affine $(f(n)=4 \cdot n+$ $1, n=1,2, \ldots)$. This suggests that the students could meet a challenge when they deal with the two patterning tasks one after another. They can apply proportional reasoning in the first task, while in the second task $f(n)$ is not proportional to $n$, though the change in the number of matchsticks $\Delta f(n)$ is proportional to $\Delta n, \Delta f(n)=4 \cdot \Delta n$. A recursive formula approach to the task Pattern 2 would be to start from the first diagram, for example, and then add the following $\operatorname{cottages}(f(n)=5+(n-1) 4, n=$ $1,2, \ldots)$. One could also use the sequence $f(1)=1+4, f(2)=1+2 \cdot 4, f(3)=1+3 \cdot 4$, and so on, to find the general diagram $f(n)=1+4 n, n=1,2, \ldots$.

\section{RESULTS}

The results exhibited here show various ways of using embryonic forms of both static and dynamic proportional reasoning. Seven excerpts within one lesson have been selected that illustrate three modes in the students' development of proportional reasoning during one lesson when scaffolded by the teacher. They represent signs of a learning trajectory for several student 
groups. The excerpts and subsequent analyses are presented under headings relating to the modes of proportional reasoning. These excerpts are chosen to show the development of embryonic proportional reasoning as clearly as possible, and also to include data from as many student groups as feasible.

\section{First Mode, Students' Initial Steps in Familiarizing Themselves with the Matchsticks and Patterns}

According to the teacher, the initial purpose of using the patterning tasks was as an introduction to algebra. The teacher explains the context of the matchstick tasks to the students.

Excerpt 1. Teacher introduction (4:005, whole-class discussion).

4. We will make some different patterns, using these. Not just any patterns, but specific patterns [...]

The teacher explains to the students that there is a difference in context between the patterns they will work with by prompting "different patterns" in Excerpt 1. By using the expression specific patterns, the teacher communicates to the students that they will work with patterns of a special type, not just any pattern. Subsequently, the teacher hands out matchsticks, suggesting that the students should use them when solving the task. In the beginning, the students start by working individually with the task Pattern 1, building and counting the number of matchsticks up to diagram $D_{3}$ in accordance with the teacher's instructions. After some time, they seem to notice a pattern structure as the teacher scaffolds them.

Excerpt 2. The students realize the relation between the number of matchsticks and the diagram number in the Pattern 1 task (9:18, whole-class discussion)

45. Teacher: How many matchsticks did you need for diagram 1? Alde?

46. Alde (Group IV): Twelve.

47. Teacher: For Diagram 1 ?

48. Alde (Group IV): Yes, four.

49. Teacher: Four matchsticks for Diagram 1, is that the same for everyone?

50. Unison: Yes.

51. Unison: No.

52. Teacher: How many did you need for one, Diagram 1 ?

53. Flynn (Group VII): Okay, Diagram 1, four.

54. Teacher: Four.

55. Teacher: How many matchsticks do you need for; do you always need for the next diagram?

56. Gerry (Group II): Four more.

57. Teacher: When you make one more diagram, Helle?

58. Helle (Group III): Sixteen.

59. Teacher: Do you always need sixteen? To make the same, the next diagram? Here we have one.

60. Helle (Group III): No, well four.

61. Teacher: Four. Okay, four more.

62. Teacher: If I now say this here, that you're going to do, one, diagram, you're going to do Diagram 5. Now you've done Diagram 1, Diagram 2, Diagram 3. What would Diagram 5 look like? Skip Diagram 4 and do Diagram 5.

63. [Several students raise their hands]

64. Teacher: Do it on your desk, let me see. [The teacher draws a table on the blackboard.]

Here in Excerpt 2 the students are beginning to notice the pattern structure, as seen when Gerry says: Four more (Turn 56) implying a recursive approach. But when the teacher scaffolds them and asks for the number of matchsticks in the next diagram, some students have difficulties deciding the number of diamonds in each pattern diagram (e.g., Alde in Turn 46, unison in Turn 51, and Helle in Turn 58). One explanation for the difficulties could be that they misinterpret the teacher's use of "always" and are therefore uncertain.

As the teacher introduces the next tool, a table, a technique for solving the task emerges as the students become familiar with the patterning task and the matchsticks, as seen in the next excerpt. The teacher scaffolds them by saying "Do it on your desk, let me see" (Turn 64), encouraging students to build the pattern with matchsticks as justification instead of giving an answer. This step of familiarizing themselves with the pattern is considered as Mode ${ }_{1}$ and illustrates that students claim that they have identified a technique for solving the task. The students use the matchsticks as tools and make conjectures about the activities when they physically build the diagrams. In her introduction, the teacher prompts the students to use matchsticks to solve the

\footnotetext{
${ }^{5}$ In the following excerpt, time is noted, for example, as 4:00, meaning 4 minutes and 0 seconds into the lesson.
} 
task. However, the teacher did not provide any clues about the mathematical structure of the pattern; this was left to the students to discover when working with the tasks.

\section{Second Mode, Students Develop Embryonic Forms of Dynamic and Static Proportional Reasoning}

In the second mode of reasoning, the student groups examine and use techniques (in the ATD sense) that have emerged from the first mode where they noticed the mathematical structure of the pattern. The techniques are referred to as embryonic forms of static and dynamic proportional reasoning (see Excerpt 3).

Excerpt 3. Illustration of embryonic dynamic proportional reasoning, in the Pattern 1 task: $D_{5}$ (16:00, whole-class discussion)

154. Teacher: How many matchsticks do you need to make 5? Diagram 5? Cleo?

155. Cleo (Group V): I think twenty but well.

155. Teacher: You think twenty, why do you think twenty?

157. Cleo (Group V): Because I accidentally did.

158. Teacher: What did you say?

159. Cleo (Group V): I, well I just did [Points to mixed-up diagrams on the bench.]

160. Teacher: Yes, but why do you think twenty now, even though you've mixed them up a bit? So, do you think twenty anyway?

161. Cleo (Group V): Two, four, six. Yes, I counted.

162. Teacher: You counted before?

163. Teacher: What do you think?

164. Elliot (Group VI): I worked out four times five.

$165-172$. [... ].

173. Teacher: What did, how did you do it Hero?

174. Hero (Group III): I took, four times five.

175. Teacher: Also, four times five.

As mentioned in the previous section, the students count matchsticks and some student groups continue with this technique when the pattern diagrams go beyond the three diagrams $\left(D_{3}\right)$ displayed on paper: Two, four, six. Yes, I counted (Turn 161, Cleo). However, some student groups apply another technique as described in Excerpt 4. The majority of the students starts to multiply the diagram number by the number of matchsticks composing one diamond: I worked out four times five $(f(5)=4 \cdot 5)($ Turn 164 , Elliot) (see Formula 1). Seeing that Elliot is considering both the diamond and the sticks at the same time, this is regarded as the initial step in the development of proportional reasoning, and it is called Mode2. Furthermore, Elliot's assumption illustrates that some students start by using proportional reasoning as a technique for solving the task. The mathematical conjecture $(f(\mathrm{n})=4 \cdot \mathrm{n}$ ) (see Formula 1 ) is highlighted for all students when the teacher clarifies in Turn 170, Four matchsticks for each. Thus, the pattern structure is once again displayed for the students while they are examining and refining their techniques to solve the tasks. Furthermore, the findings show that student groups also used another technique for solving the task Pattern 1 . This technique emerges when the teacher begins to use the previously drawn table on the blackboard. This is displayed in Excerpt 4.

Excerpt 4. Illustration of embryonic static proportional reasoning, in the task Pattern $1: D_{5}$ and $D_{10}(17: 00$, whole-class discussion).

200. Teacher: I thought you might already know how many there were in Diagram 10 ?

201. Teacher: [Points at a student.]

202. Elia (Group VI): I know it.

203. Teacher: Well then, what have you got? How many is it?

204. Elia (Group VI): Forty.

205. Teacher: Forty, why?

206. Elia (Group VI): Because, well, when it's five then, then it's twenty.

207. Teacher: [Nodding]

208. Elia (Group VI): If you take five more then it will be, forty.

209. Aisha (Group IV): Ten times four.

210. Teacher: Forty, because it's twice as much as in ten. [Pointing at the number of sticks for D5 and D10.] Shall we check? Or have you checked? You have laid out here, ten boxes.

211. Elliot (Group VI): [Nodding]

212. Teacher: Is that forty? 
213. Elliot (Group VI): Yes.

214. Teacher: It is. Ok.

In Turn 206, Elia suggests: Because, well, when it's five then, then it's twenty $(n / f(n)=5 / 20)$, followed by: Ifyou take five more then it will be, forty. $(5 / 20=10 / 40)$ (Turn 208) (see Formula 2). Elia thus uses a technique that can be described as using an external relationship between the diagram number $(n=10)$ in $\mathrm{D}_{10}$ and the corresponding number of matchsticks, $f(10)$, and comparing it to the external relationship between the diagram number $(n=5)$ in $D_{5}$ and the corresponding number of matchsticks, $f(5)$. On the other hand, the teacher scaffolds the students to use an internal relationship by saying: Forty, because it's twice as much $(f(10) / f(5)=40 / 20)$ (Turn 210) (see Formula 2) and pointing at 20 in the table $(f(5))$, and afterwards pointing at the pattern $\mathrm{D}_{10}$. These ways of reasoning can be regarded as instances of static proportional reasoning that characterize Mode $_{2}$. There is a mix of techniques used in the class, and some students make the shift between static and dynamic relationships effortlessly, for example, when Aisha suggests: Ten times four (Turn 209) (see Formula 1). Furthermore, a mathematical conjecture can be made of Elia's observation in Turn 208 about splitting the ten diamonds into two diagrams with five diamonds, $(f(5)+$ $f(5)=f(10))$. This can be interpreted as an intuitive understanding of linearity.

The video analysis discloses difficulties for student groups linked to the construction and implementation of the task, i.e., the interval length and/or the non-consecutive diagrams, as illustrated in Excerpt 5.

Excerpt 5. Illustration of difficulties in the Pattern 1 task: $D_{5}, D_{10}$ and $D_{20}$ (17:00, whole-class discussion).

214. Fidel (Group VII): Twenty there, it should be eighty for twenty. [Pointing at the table on the blackboard]

215. Teacher: It should be eighty there. [Pointing at $D_{20}$ on the blackboard]

216. Fidel (Group VII): No, I meant sixty.

217. Teacher: Yes, what do you mean?

218. Fidel (Group VII): Sixty.

219. Teacher: Why?

220. Fidel (Group VII): Because twenty, no, if you add twenty to forty, you get sixty and twenty boxes, or have I got it all wrong or what?

221. Cam (Group V): No.

222. Teacher: No, say it out loud so that everyone can hear.

$223-227$. [...].

228. Teacher: Once again Fidel!

229. Fidel (Group VII): Because five, was twenty and ten [Teacher points on the board] is twice as much, as five, and then, what's it called, twenty is twice as much as ten so that made sixty because, they always, because, you add twenty all the time, because, yes.

230. Teacher: Do you follow? Do you agree?

231. Unison: No.

232. Unison: Yeah.

233. Unison: No.

In Excerpt 5 difficulties related to interval length are exemplified when Fidel recognizes proportional relationships in the table by saying: Because five, was twenty and ten, [... ] is twice as much, as five (Turn 229) (see Formula 2). But later in Fidel's explanation, she changes techniques and wrongly adds 20 matchsticks: because, you add twenty all the time (Turn 229) (see Formula 1), and she gets 60 matchsticks instead of 80 . From this observation, it seems that Fidel is not aware of the change of the interval lengths from five diagrams to ten diagrams in the table because she shows signs of a recursive approach to the pattern structure when she says, "add twenty all the time." Another observed difficulty is the students' inability to move between internal and external relationships also caused by the non-consecutive diagrams in the table. Fidel tries to establish the (external) relationship between $f(20)$ and $n=20$ by using the internal relationship between $n=5$ and $n=20:[\ldots]$ ten, [... ] is twice as much, as five (Turn 229), and: twenty is twice as much as ten (Turn 229), but fails to do so correctly by suggesting $f(20)=f(5)+f(5)+f(5)=60$ instead of $f(20)=2 \cdot 2 \cdot f(5)=80$ : add twenty to forty, you get sixty and twenty boxes (Turn 220). In Figure 4, the external relationship is illustrated by 5:20 and 10:40 and the internal relationship is illustrated both by 10:20 and 20:40 and by the incorrect answer 40:60. Fidel's struggle in both cases with the non-consecutive diagrams opens up a ZPD and provides opportunities for the teacher to start scaffolding by inserting questions about the interval lengths. 


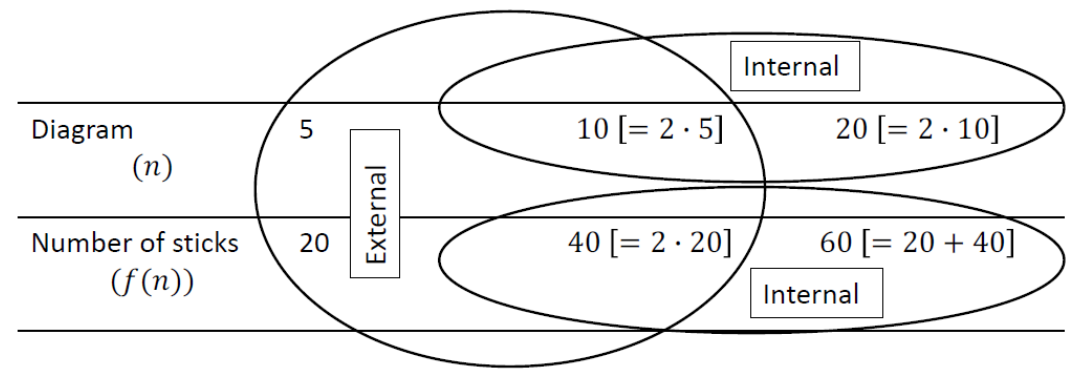

Figure 4. Illustration of Fidel's reasoning (Group VII): Examples of alternation between external and internal relationships

Together these results provide insights into how students work with and develop different techniques to deal with the pattern. In Mode 2 , students tentatively use new techniques such as static and dynamic proportional reasoning, while figuring out under what conditions each is valid, when they check the answers by building with matchsticks.

To summarize the results in Mode $_{2}$, the student groups test and seem to use both dynamic and static proportional reasoning to solve the task Pattern 1. Furthermore, the student groups make adjustments between internal and external relationships, i.e., the diagram number $(n)$ and the number of matchsticks $(f(n))$. Some student groups manage to shift between these techniques, but for other student groups, these shifts were not without complications. These difficulties are linked to the non-consecutive diagram numbers $(n)$ that seem to prompt Fidel (Group VII), for example, to make conjectures about how to calculate the number of matchsticks $(f(n))$.

\section{Third Mode, a New Situation Where Students Realize Proportional Reasoning Does Not Work and Change Techniques}

When the student groups first receive the task Pattern 2 from the teacher, they begin the task by using previously discovered embryonic forms of proportional reasoning from the Pattern 1 (see the summary of students' comments in Figure 5).

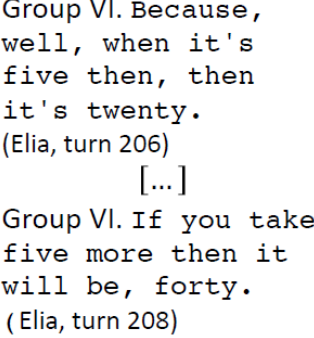

Illustration from Mode $_{3}$ :
new pattern introduced
(Fishermen's cottages)

Multiply diagram number $(n)$ by number of sticks in the first diagram $f(n)$ (embryonic dynamic proportional reasoning)

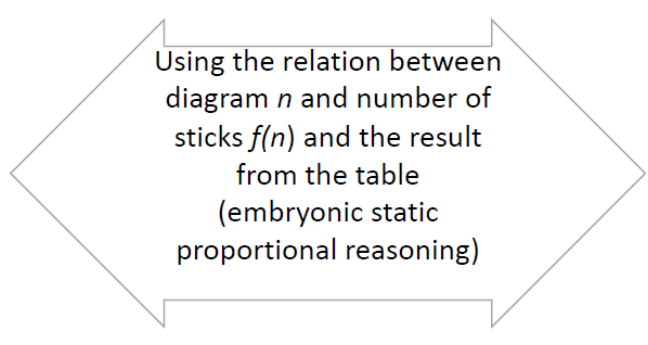

Figure 5. An analytical comparison between embryonic proportional reasoning used in tasks Pattern 1 and Pattern 2. Group III is the group with two students

The analysis shows that the students discover and comment on the fact that the earlier techniques are not compatible with Pattern 2 task. Five student groups realize the differences between the two patterning tasks. This is displayed in Mode (see Excerpt $^{2}$ $6)$.

Excerpt 6. Illustration of noticing pattern structure in the Pattern 2 task: $D_{2},(32: 00$, teacher-student group discussion).

445. Flynn (Group VII): Because they are together, they are not separated.

Excerpt 6 shows how Flynn has realized the central problem that two adjacent cottages in the Pattern 2 have a shared matchstick. He corrects himself and removes one of the two middle matchsticks between two Fishermen's cottages (see Figure 6). However, this has mathematical consequences which Flynn's group does not manage to work out on their own so they turn to the teacher for help. This indicates that a ZPD opens up in which the teacher may be in a position to scaffold Flynn. However, instead of using this opportunity, the teacher refers back to the more primitive technique of building the pattern with matchsticks and then counting the number of matchsticks. 


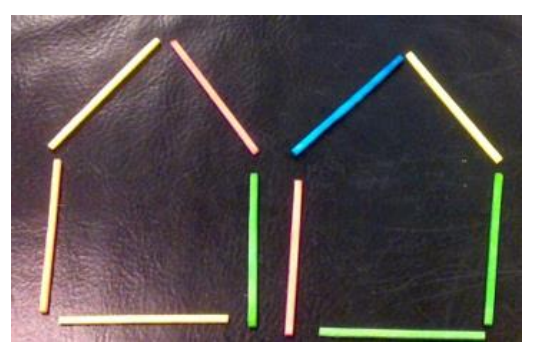

Figure 6. Student-created diagram of Fishermen's cottages in the Pattern 2 task (Picture recreated by the author)

Although five student groups (I, II, III, VI, VII) realize how the cottages are connected, only two student groups (II, III) modify their technique to find a general rule for calculating $f(n)$ for every diagram number $n$. Being able to take this step of searching for a new rule is regarded as Mode 3 in my analysis. Three other student groups (I, VI, VII) go back to counting matchsticks, maybe because of the teacher's suggestion to do so. Two student groups (II, III) operate on the worksheet and combine the three given diagrams to calculate $f(n)$ for larger $n$. The table constructed by Hero (Group III) is shown in Figure 7. The table shows that Hero (Group III) has finished the Pattern 2 task correctly.

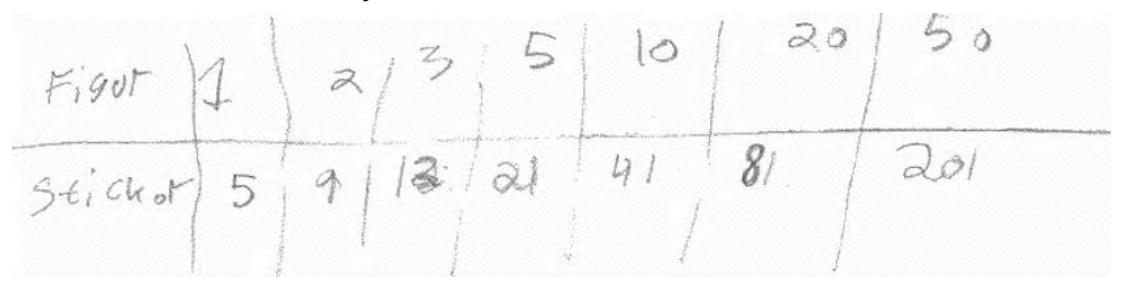

Figure 7. A student's table for the task Pattern 2. The students (Group III) have finished the task successfully. The word "figur" in the table is translated as "diagram" in the article

Groups II and III construct a technique for the task Pattern 2 that is valid for all $n$. They use their conjectures from the table with the Pattern 1 and realize that only one matchstick differs. Hero (Group III) explains it to the whole class, see Excerpt 7.

Excerpt 7. Illustration of finding a general technique for calculating $f(n)$ for every diagram number $n$ in the Pattern 2 task, (37:30, whole-class discussion)

568. Hero (Group III): Then I was a bit clever here, because, since there are two of those houses, you take, one, the number of houses, it is, minus that, sort of [points in the table] and then you have to take it away, from the number you had from the start, it's really complicated.

\section{Summary}

When the teacher presents the task, Pattern 2, students first try the same techniques as they used in the first task. Some of them realize the difference in pattern structure (Excerpt 6), and by managing to adjust their techniques they can move on to the general formula (Excerpt 7). Students perceive a new technique to handle a new situation where proportional reasoning fails, thus showing that they are actually able to make the required generalization in one lesson. But even though some other students (Groups V, VIII) also manage to notice the difference between the tasks Pattern 1 and Pattern 2, they still fail to find a general rule for calculating $f(n)$ for every $n$. Instead of showing progress, they regress to the earlier techniques in search of a solution.

The root of the students' failure to generalize in the Pattern 2 task is the properties of the affine function. When the students face the task Pattern 1 followed by the task Pattern 2, they notice the differences in the pattern structure, which can be described mathematically as the challenge of moving between linear and affine functions. This is confirmed by the fact that for some students, a ZPD opens up when they handle Pattern 2. This in turn leads to opportunities for scaffolding in different ways (for example by questions, counting, and building).

The results of this study are summarized in Figure 8 in a graphic representation of the three modes of reasoning. The arrows describe the observed learning trajectory for all students. It is important to note that it is not certain that the students always arrive at the modes in this order as their learning trajectories are not the same. Some modes may be skipped, and there may be regressions. Figure 8 illustrates the students' progression regarding proportional reasoning and that this progression is not linear. This is shown by some students returning to earlier techniques when they are solving problems and others returning to building and counting diagrams. At least two student groups realize how the cottages are attached but nevertheless return to building and counting matchsticks. 


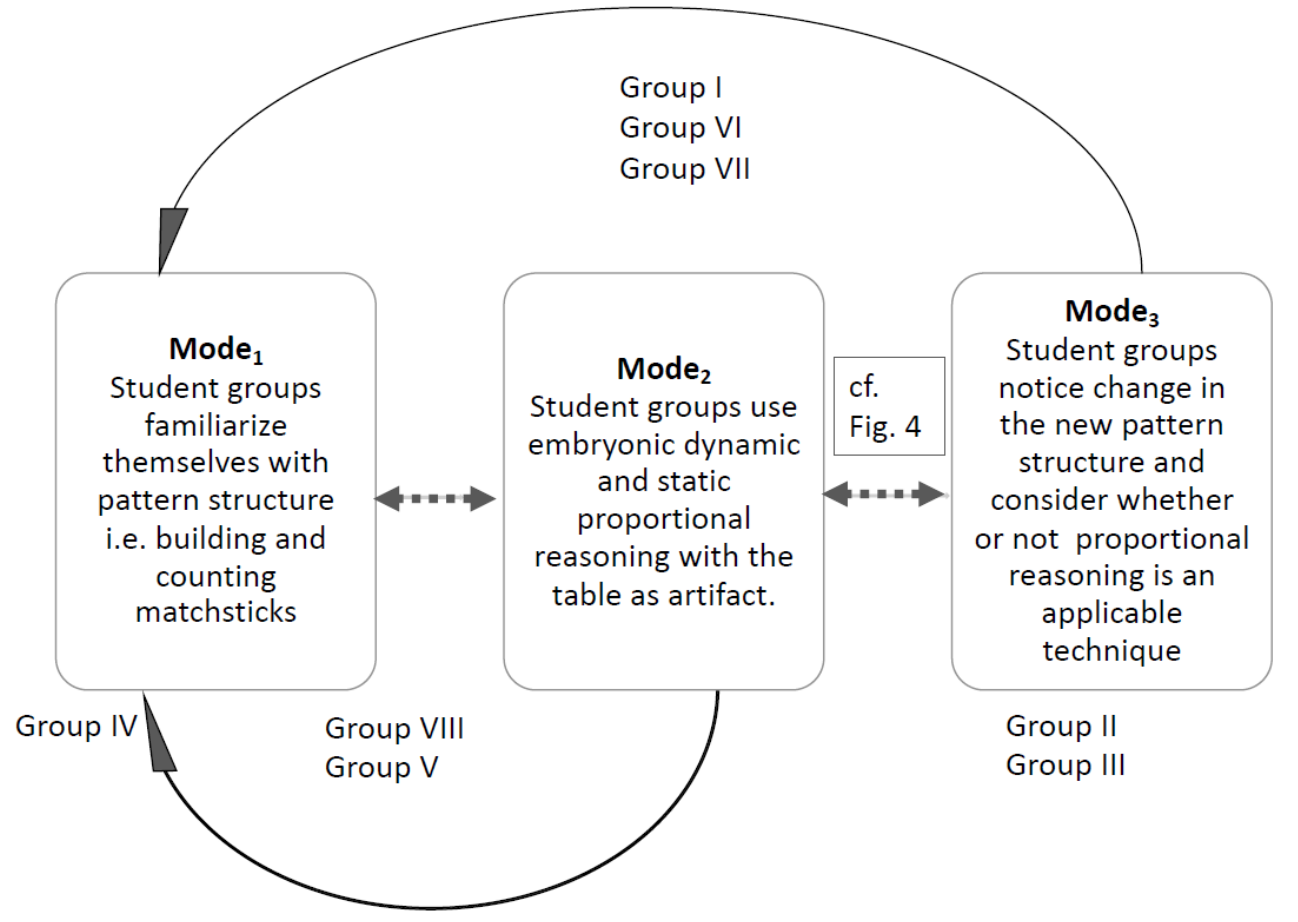

Figure 8. Students' observed learning trajectories for proportional reasoning collected into three modes (Mode ${ }_{1}$, Mode 2 , and $\mathrm{Mode}_{3}$ ). The dotted arrows indicate the empirical outcome, i.e., that the students move back and forth between the modes of proportional reasoning

The empirical results suggest a learning trajectory, described by three modes of proportional reasoning, during one lesson. However, the move from one mode to another does not happen at one particular point in time but is more of an ongoing process. An additional observation is that two groups were able to find the reason for their success in the first task and for the subsequent failure of their initial techniques in the second task. These groups were able to change techniques appropriately in the second task and obtain correct solutions to both tasks during one lesson. The dotted arrows indicate that students sometimes return to a simpler technique.

\section{DISCUSSION}

There are a few studies concerning how the development of student groups' learning processes for proportional reasoning occurs. Lybeck (1981) shows that students use internal proportionalities intuitively but can have difficulties with external proportionalities without explicit teaching. In addition, several reports (e.g., Van Dooren et al., 2005) show that students have difficulties determining when proportional reasoning could be applied as a result of not knowing the difference between linear and affine situations. The present study is a microgenetic analysis of the ways students approach modes of reasoning that involve recognizing situations where proportionality is applicable. The results are summarized in terms of a learning trajectory (Figure 8). The combination of a microgenetic approach (Cole, 1996) and techniques (in the sense in which the term is used in ATD) in a single case study (Lincoln \& Guba, 1985) made a detailed analysis possible. The focus of the analysis was on how students handled proportional reasoning when working with patterning tasks, as well as how they altered their techniques when proportional reasoning was not applicable. The results of this study confirm that learning is seldom a linear process, but more of a back-andforth movement. In the following section, these results are discussed, guided by the two intertwined research questions.

\section{Student Groups' Emerging Proportional Reasoning in a Patterning Task with Proportional Relationships}

The most interesting result of this empirical single case study is the student groups' development of proportional reasoning during a single lesson. The learning process started with the students familiarizing themselves with the pattern, noticing the linear structure of the pattern and finding a valid technique to use for the particular situation. When the students were given a different pattern, they noticed its affine structure and some of the student groups adopted a technique that was suitable for the new situation, see Figure 8.

Even though the students were not formally taught about proportional reasoning in the teacher's introduction, the data indicate that they spontaneously used techniques of embryonic proportional reasoning when working with the patterning tasks and matchsticks. These first attempts at calculating the number of sticks show similarities with the Vygotskian perspective on the learning of mathematical concepts (Vygotsky, 1934/1986), where proportionality may be seen both as a spontaneous concept and as a scientific concept. These signs of students' intuitive learning of proportional relationships are in line with findings regarding learning processes in several earlier studies (e.g., Inhelder \& Piaget, 1958; Lamon, 2007; Vygotsky, 1934/1986). Overall, this study strengthens the idea that proportional reasoning can be considered as a spontaneous concept, from observations of the students' intuitive understanding of proportional relationships. 
Another result regarding the learning process relates to when the students faced the challenge that the diagram numbers ( $\mathrm{n}$ ) in the list were no longer consecutive. Because of this change of mathematical structure, some student groups gave an erroneous suggestion for $f(20)$, generalizing the observations incorrectly: twenty is twice as much as ten so that made sixty (Excerpt 5, Turn 229). A possible interpretation of this is that the presence of proportional relationships in the table initiated the use of proportional reasoning as a spontaneous concept. The students' words and actions display their actual level of development, and the teacher scaffolds them when asking: Once again Fidel! (Excerpt 5, Turn 228) and: Do you follow? Do you agree? (Excerpt 5, Turn 230). This situation is an opportunity for the teacher to introduce the scientific concept (proportionality) as the students are already familiar with the corresponding spontaneous concept (proportional reasoning).

More signs of ongoing learning processes were discerned in several cases as students experienced what seemed to be insights regarding the difference in structure between the two patterning tasks. The students could not, however, move on without scaffolding from the teacher. This resulted in a zone of proximal development being opened up. The challenge of the structure triggered the students to realize these differences: Because they are together, they are not separated (Excerpt 6, Turn 445). Here, a crucial recontextualization of mathematical significance appears when the student expresses how the two patterns differ with respect to the joining of adjacent elements (diamonds and cottages). The teacher's scaffolding on these occasions helped the students to perceive the table as a contextually relevant cultural tool and not only as a structured set of lines.

This study focuses on the mathematical structure of the patterns and on how student groups use spontaneous concepts. This is in line with Strømskag Måsøval's (2011) study about pre-service teachers' work with patterns, where activities involving relating the pattern structures to numerical sequences were seen as an advantage for student groups' development of algebraic thinking. It seems likely that the learning trajectory presented in this study may be applicable to other patterning activities with matchsticks. This assumption is strengthened by the example where the students begin by making conjectures regarding the connection between the number of matchsticks $f(n)$ and diagram number $(n)$ : Four more (Excerpt 2, turn 56). While working with the patterning tasks and matchsticks, they begin to grasp the commonality of numerical and spatial structures of the patterns. The present study, therefore, points at a possible way to initiate algebraic thinking as previously described by Radford (2011a, 2011b).

\section{Two Challenges That Create Opportunities for Learning}

The results show that the use of non-consecutive diagram numbers promotes structural awareness, and this is in line with earlier studies (e.g., Küchemann, 2010; Wilkie, 2016). It was observed that the order of terms produced two challenges for the students. These two challenges are seen as crucial steps for the student groups' learning development.

The first challenge for the students in the Pattern 1 task is the shift between internal and external proportionality called for by the use of a table (see Figure 4). These shifts from external to internal static proportional reasoning could be an explanation for the difficulties in Group VII, as shown by Fidel's argumentation. In Excerpt 5, Turn 229, we see that Fidel (Group VII) makes the shift but also makes mistakes with adding when she goes from: five, was twenty and ten to: [...] ten, [...] is twice as much, as five [...]. However, after making this shift, she reverts to a recursive technique: because, you add twenty all the time. The finding regarding the use of recursive techniques was complementary finding and shows that students already have spontaneous techniques. This presents an opportunity for learning and may be of advantage in teaching proportional reasoning. The discoveries of difficulties encountered when alternating between internal and external proportionality are consistent with earlier research by Freudenthal (1983) and Lybeck (1981). An additional obstacle to understanding and using the table as a tool is that the quantities $n$ and $f(n)$ in the table belong to different measure spaces (Kirsch, 1969; Vergnaud, 1983). This suggests that students need to learn how to use external relationships and proportionality in different contexts by being explicitly taught by the teacher, as Lybeck (1981) already points out in his study of proportionality.

The second challenge for the students is the specific sequence of the two patterning tasks, where the linear function in the Pattern 1 task is followed by the affine function in the Pattern 2 task. However, the students are forced to reconsider the pattern structure after failing to get the correct answer, thereby realizing that in the new situation, the techniques from the first pattern are not applicable. At this point, some students are able to progress to a new viable technique, while others regress to the technique of building diagrams and counting the number of matchsticks. These results are in agreement with research in earlier studies about the overuse of linearity (Lamon, 2007; Stacey, 1989; Van Dooren et al., 2005). Furthermore, this study adds to the research carried out by Burgos and Godino (2020) regarding opportunities to distinguish proportional from non-proportional situations. This study also extends Wilkies' (2016) results by suggesting explanations for the fact that only a few students could generalize the Pattern 2 task. The results support the idea that students use proportional reasoning regardless of its applicability (e.g., Stacey, 1989), which is relevant in that, as Lamon (2007) pointed out, learning something involves knowing both what something is and what it is not.

\section{CONCLUSIONS AND IMPLICATIONS}

The study of a single case, with one teacher and her class, contributes to supporting the aim of increasing our knowledge about how students' proportional reasoning develops. A conclusion drawn here is that the studied tasks fulfil two conditions for enabling proportional reasoning. First, the students handle the patterns by using tools (the matchsticks and table); second, in this way they are given a context from which it is possible to generalize. The results of this study may enrich teachers' understanding of how students develop proportional reasoning so that the teachers can: analyze theoretical models of proportionality and predict students' strategies and ideas, encourage students with the help of the analyzed learning trajectory, and rejoice in their students' progress within proportional reasoning. Even though this is a case study involving only one lesson, it contributes to an understanding of learning trajectories for proportional reasoning by shedding light upon how cultural tools and tasks can be used 
in this context. The findings thus suggest that patterning tasks are suitable for teaching proportional reasoning if they fulfil the following conditions. First, they should include the handling of both linear and strictly affine functions. Second, they should use non-consecutive diagram numbers, in order to be a challenge for the students. Third, for optimal learning opportunity, the linear pattern should precede the strictly affine one. Such challenges would provide opportunities for the students to develop deeper knowledge about proportional reasoning.

Author notes: Author has agreed with the results and conclusions.

Funding: The study is funded by the Joint Committee for Nordic Research Councils for the Humanities and the Social Sciences (NOS-HS) through a grant to the Linnaeus Centre for Research on Learning, Interaction and Mediated Communication in Contemporary Society (LinCS), the Swedish Research Council (dnr 349-2006-146), and the Research School at the Centre for Educational Science and Teacher Research (CUL), Gothenburg University and The Royal Society of Arts and Sciences in Gothenburg.

Acknowledgements: This article is a development of a contribution to the PME 37 (Lundberg \& Hillman, 2013). Author wishes to thank the researchers in the VIDEOMAT project for the great help in collaborative video analysis.

Declaration of interest: No conflict of interest is declared by author.

\section{REFERENCES}

Bosch, M. (1994). La dimensión ostensiva en la actividad mathemática: El caso de la proporcionalidad [The ostensive dimension in mathematical activity: The case of proportionality] [Doctoral dissertation, Universitat Autónoma de Barcelona].

Bosch, M., \& Gascón, J. (2006). Twenty-five years of didactic transposition. International Commission on Mathematical Instruction Bulletin, 58, 51-65.

Burgos, M., \& Godino, J. D. (2020). Semiotic conflicts in the learning of proportionality: Analysis of a teaching experience in primary education. International Electronic Journal of Mathematics Education 15(3). https://doi.org/10.29333/iejme/7943

Chevallard, Y. (2006). Steps towards a new epistemology in mathematics education. In M. Bosch (Ed.), Proceedings of the 4th congress of the European society for research in mathematics education (pp. 21-30). FUNDEMI-1QS and ERME.

Chevallard, Y., Bosch, M., \& Kim, S. (2015). What is a theory according to the anthropological theory of the didactic? In K. Krainer, \& N. Vondrová (Eds.), Proceedings of the ninth congress of the European society for research in mathematics education (pp. 26142620). Charles University in Prague, Faculty of Education and ERME.

Cole, M. (1996). Cultural psychology: A once and future discipline. The Belknap Press.

Confrey, J., Maloney, J., Nguyen, K., Mojica, G., \& Myers, M. (2009). Equipartitioning/splitting as a foundation of rational number reasoning using learning trajectories. In M. Tzekaki, M. Kaldrimidou, \& C. Sakonidis (Eds.), Proceedings of the 33rd conference of the international group for the psychology of mathematics education (Vol. 1, pp. 1-8). PME.

Cramer, K., \& Post, T. (1993). Connecting research to teaching: Proportional reasoning. Mathematics Teacher, 86(5), $404-407$. https://doi.org/10.5951/mt.86.5.0404

Del Río, P., \& Álvarez, A. (2007). Inside and outside the zone of proximal development: An ecofunctional reading of Vygotsky. In H. Daniels, M. Cole, \& J. Wertsch (Eds.), The Cambridge companion to Vygotsky (pp. 276-303). Cambridge University Press. https://doi.org/10.1017/CCOL0521831040.012

Dewey, J. (1916/1980). Logical objects. In J. A. Boydston (Ed.), The Middle Works of John Dewey, Volume 10, 1899 - 1924: Journal articles, essays, and miscellany published in the 1916-1917 period, with an introd. by Lewis E. Hahn (Vol. 10: 1916-1917, pp. 8997). Southern Illinois University Press.

Euclid, \& Heath, T. L. (1956). The thirteen books of Euclid's elements. Dover.

Freudenthal, H. (1983). Didactical phenomenology of mathematical structures. Reidel Publishing Company. https://doi.org/ 10.1007/0-306-47235-X

García, F. (2005). La modelización como herramienta de articulación de la matemática escolar. De la proporcionalidad a las relaciones funcionales [Modeling as an articulation tool for school mathematics. From the proportionality to the functional relations] [Doctoral dissertation, Universidad de Jaén].

Goodwin, C. (1994). Professional vision. American Anthropologist, 96(3), 606-633. https://doi.org/10.1525/aa.1994.96.3.02a00100

Granott, N. (1998). Unit of analysis in transit: From the individual's knowledge to the ensemble process. Mind, Culture, and Activity, 5(1), 42-66. https://doi.org/10.1207/s15327884mca0501_4

Granott, N., \& Parziale, J. (2002). Microdevelopment: A process-oriented perspective for studying development and learning. In J. Parziale, \& N. Granott (Eds.), Microdevelopment: Transition processes in development and learning (pp. 1-28). Cambridge University Press. https://doi.org/10.1017/CB09780511489709.00

Heath, C., Hindmarsh, J., \& Luff, P. (2010). Video in qualitative research, analysing social interaction in everyday life. SAGE. https://doi.org/10.4135/9781526435385

Inhelder, B., \& Piaget, J. (1958). The growth of logical thinking from childhood to adolescence: An essay on the construction of formal operational structures. Routledge and Kegan, Paul Ltd. https://doi.org/10.4324/9781315009674

Jordan, B., \& Henderson, A. (1995). Interaction analysis: Foundations and practice. The Journal of the Learning Sciences, 4(1), 39103. httpS://doi.org/10.1207/s15327809jls0401_2 
Kieran, C. (2018). Seeking, using, and expressing structure in numbers and numerical operations: A fundamental path to developing early algebraic thinking. In C. Kieran (Ed.), \& G. Kaiser (Series Ed.), ICME-13 Monographs. Teaching and learning algebraic thinking with 5- to 12-year-olds: The global evolution of an emerging field of research and practice (pp. 79-106). Springer Nature. https://doi.org/10.1007/978-3-319-68351-5

Kilhamn, C., \& Röj-Lindberg, A.-S. (2012). Seeking hidden dimensions of algebra teaching through video analysis. In B. Grevholm, P. S. Hundeland, K. Juter, K. Kislenko, \& P. E. Persson (Eds.), Nordic research in mathematics education, past, present and future (pp. 299-326). Cappelen Damm Akademisk.

Kirsch, A. (1969). Eine Analyse der sogenannten Schlussrechnung. [An analysis of the so-called final invoice]. MathematischePhysikalische Semsterberichte [Mathematical-Physical Semester Reports], 16(1), 41-55.

Küchemann, D. (2010). Using patterns generically to see structure. Pedagogies: An International Journal, 5(3), $233-250$. https://doi.org/10.1080/1554480X.2010.486147

Lamon, S. (2007). Rational numbers and proportional reasoning: Toward a theoretical framework for research. In F. K. Lester (Ed.), Second handbook of research on mathematics teaching and learning: A project of the National Council of Teachers of Mathematics (pp. 629-667). Information Age Publishing.

Lannin, J., Barker, D., \& Townsend, B. (2006). Recursive and explicit rules: How can we build student algebraic understanding? The Journal of Mathematical Behavior, 25, 299-317. https://doi.org/10.1016/j.jmathb.2006.11.004

Lincoln, Y. S., \& Guba, E. (1985). Naturalistic inquiry. SAGE. https://doi.org/10.1016/0147-1767(85)90062-8

Lobato, J., \& Ellis, A. (2010). Developing essential understanding of ratios, proportions and proportional reasoning. National Council of Teachers of Mathematics.

Lobato, J., \& Walters, D. (2017). A taxonomy of approaches to learning trajectories and progressions. In J. Cai (Ed.), Compendium for research in mathematics education (pp. 74-101). National Council of Teachers of Mathematics.

Lüken, M. (2012). Young children's structure sense. Journal für Mathematik-Didaktik [Journal for Mathematics Didactics], 33(2), 263285. https://doi.org/10.1007/s13138-012-0036-8

Lundberg, A. L. V. (2011). Proportionalitetsbegreppet i den svenska gymnasiematematiken - en studie om läromedel och nationella prov [The concept of proportionality in the Swedish upper secondary school mathematics - a study of textbooks and national examination] [Licentiate thesis, Linköping University].

Lundberg, A. L. V., \& Hillman, T. (2013). Student-driven proportional reasoning approaches to an early algebra task. In A. M. Lindmeier \& A. Heinze (Eds.), Proceedings of the 37th international group for the psychology of mathematics education (Vol. 5 , pp. 112). PME.

Lybeck, L. (1981). Arkimedes i klassen: En ämnespedagogisk berättelse [Archimedes in the classroom: A narrative on the didactics of subject matter] [Doctoral dissertation, Gothenburg University].

Maloney, A., Confrey, J., \& Nguyen, K. H. (2014). Learning over time: Learning trajectories in mathematics education. Information Age Publishing. https://ebookcentral.proquest.com

Mason, J., Stephens, M., \& Watson, A. (2009). Appreciating mathematics structure for all. Mathematics Education Research Journal, 21(2), 10-32. https://doi.org/10.1007/BF03217543

Miyakawa, T., \& Winsløw, C. (2009). Didactical designs for students' proportional reasoning: An "open approach" lesson and a "fundamental situation". Educational Studies in Mathematics, 72(2), 199-218. https://doi.org/10.1007/s10649-009-9188-y

Mulligan, J., \& Mitchelmore, M. (2009). Awareness of pattern and structure in early mathematical development. Mathematics Education Research Journal, 21(2), 33-49. https://doi.org/10.1007/BF03217544

Radford, L. (2011a). Embodiment, perception, and symbols in the development of early algebraic thinking. In B. Ubuz (Ed.), Proceedings of the 35th conference of the international group for the psychology of mathematics education (Vol. 4, pp. 17-24). PME.

Radford, L. (2011b). Grade 2 students' non-symbolic algebraic thinking. In J. Cai, \& E. Knuth (Eds.), Early algebraization - a global dialogue from multiple perspectives (Vol. 2, pp. 303-322). Springer. https://doi.org/10.1007/978-3-642-17735-4_17

Säljö, R. (1991). Learning and mediation: Fitting reality into a table. Learning and Instruction, 1(3), 261-272. https://doi.org/ 10.1016/0959-4752(91)90007-u

Säljö, R. (2009). Learning, theories of learning, and units of analysis in research. Educational Psychologist, 44(3), $202-208$. https://doi.org/10.1080/00461520903029030

Säljö, R. (2011). Learning in a sociocultural perspective. In V. G. Aukrust, (Ed.), Learning and cognition in education (pp. 59-63). Elsevier.

Shield, M., \& Dole, S. (2013). Assessing the potential of mathematics textbooks to promote deep learning. Educational Studies in Mathematics, 82(2), 183-199. https://doi.org/10.1007/s10649-012-9415-9

Siegler, R. (2006). Microgenetic analyses of learning. In D. Kuhn, \& R. Siegler (Eds.), Handbook of child psychology (Vol. 2: Cognition, perception and language, pp. 464-510). Wiley. https://doi.org/10.1002/9780470147658.chpsy0211

Simon, M. A. (1995). Reconstructing mathematics pedagogy from a constructivist perspective. Journal for Research in Mathematics Education, 26, 114-145. https://doi.org/10.2307/749205 
Simon, M. A. (2018). An emerging methodology for studying mathematics concept learning and instructional design. The Journal of Mathematical Behavior, 52, 113-121. https://doi.org/10.1016/j.jmathb.2018.03.005

Stacey, K. (1989). Finding and using patterns in linear generalising problems. Educational Studies in Mathematics, 20(2), $147-164$. https://doi.org/10.1007/bf00579460

Strømskag Måsøval, H. (2011). Factors constraining students' establishment of algebraic generality in shape patterns: A case study of didactical situations in mathematics at a University College [Doctoral dissertation, University of Agder].

Swedish National Agency for Education. (2001). Compulsory school: Syllabuses. Fritzes.

Swedish National Agency for Education. (2011). Curriculum for the compulsory school, preschool class, and the leisure-time centre, Lgr2011 (revised). Swedish National Agency for Education. https://www.skolverket.se/publikationer?id=3984

The Swedish Research Council. (2007). CODEX: Rules and guidelines for research. https://codex.uu.se

Tjoe, H., \& Torre, J. (2014). On recognizing proportionality: Does the ability to solve missing value proportional problems presuppose the conception of proportional reasoning? The Journal of Mathematical Behaviour, 33, 1-7. https://doi.org/ 10.1016/j.jmathb.2013.09.002

Van Dooren, W., De Bock, D., Hessels, A., Janssens, D., \& Verschaffel, L. (2005). Not everything is proportional: Effects of age and problem type on propensities for overgeneralization. Cognition and Instruction, 23(1), 57-86. https://doi.org/ 10.1207/s1532690xci2301_3

Van Dooren, W., De Bock, D., Janssens, D., \& Verschaffel, L. (2008). The linear imperative: An inventory and conceptual analysis of students' overuse of linearity. Journal for Research in Mathematics Education, 39(3), 311-342. https://doi.org/10.2307/30034972

Vergnaud, G. (1983). Multiplicative structures. In R. Lesh, \& M. Landau (Eds.), Acquisition of mathematics concepts and processes (pp. 128-175). Academic Press.

Vygotsky, L. (1930/1978). Mind in society: The development of higher psychological processes. In M. Cole, V. John-Steiner, S. Scribner, \& E. Souberman (Eds.). Harvard University Press.

Vygotsky, L. (1934/1986). Thought and language (A. Kozulin, Trans.). MIT Press.

Weber, E., Walkington, C., \& McGalliard, W. (2015). Expanding notions of "Learning trajectories" in mathematics education. Mathematical Thinking and Learning, 17(4), 253-272. https://doi.org.ezproxy.ub.gu.se/10.1080/10986065.2015.1083836

Wells, G. (1999). Dialogic inquiry: Towards a sociocultural practice and theory of education. Cambridge University Press. https://doi.org/10.1017/cbo9780511605895

Werner, H. (1948). Comparative psychology of mental development. International University Press.

Wertsch, J. (1985). Vygotsky and the social formation of mind. Cambridge University Press.

Wilkie, K. (2016). Students' use of variables and multiple representations in generalizing functional relationships prior to secondary school. Educational Studies in Mathematics, 93(3), 333-361. https://doi.org/10.1007/s10649-016-9703-x

Wood, D., Bruner, J., \& Ross, G. (1976). The role of tutoring in problem solving. Journal of Child Psychology and Psychiatry, 17(2), 89-100. https://doi.org/10.1111/j.1469-7610.1976.tb00381.x 